\title{
RESEARCH OF INTEGRAL CHARACTERISTICS OF PROCESS OF HEATTRANSFER IN THE SENSITIVE ELEMENT OF RESISTIVE TEMPERATURE DETECTOR
}

\author{
Yuliana K. Atroshenko ${ }^{1,}$, Anna V. Abramova ${ }^{1}$, and Pavel A. Strizhak ${ }^{1}$ \\ ${ }^{1}$ National Research Tomsk Polytechnic University, 634050 Tomsk, Russia
}

\begin{abstract}
Heattransfer models in a sensitive element of the resistive temperature detector taking into account temperature dependence of heatphysical characteristics of elements of the sensor are developed. The assessment of the relative deviation of results of numerical research of integral characteristics of process of heattransfer in a sensitive element of the sensor from the data obtained by means of the model which isn't considering influence of temperature on heatphysical properties of substances is executed. It is shown that the relative error of computation makes from $7,3 \%$ to $14,9 \%$ depending on type of the sensor and the taken temperature.
\end{abstract}

\section{Introduction}

Temperature - one of the key parameters characterizing a status of technology equipment and efficiency of course of technological processes [1,2]. The share of systems of measurement and regulation of temperature makes to $50 \%$ (in some cases - to $80 \%$ ) from the total amount of monitoring systems of technological processes. For temperature measurement in the industry, mainly, thermoelectric converters (TEP) and resistive temperature detector (RTD) $[3,4]$ are used. One of the main methods of increase of measuring accuracy is prognostic process modeling of heattransfer in a sensitive element of the sensor. Simulation by means of numerical methods was widely adopted [5]. In this case, an important role is played by the heatphysical characteristics of materials used in researches. Often characteristics are accepted constant and independent of temperature that can lead to appearance of an additional error of computation. It is possible to minimize possible errors in this case by approximation of dependences of heatphysical properties of materials and use in numerical researches of the received approximating expressions [6-8].

The purpose of this work is modeling of process of heattransfer in RTD and comparison of results of numerical researches of the integrated characteristics of heattransfer received taking into account dependence of heatphysical properties of materials on temperature and at their constant values.

\footnotetext{
a Corresponding author: julie55@tpu.ru
} 


\section{MATEC Web of Conferences}

\section{Physical model of heat transfer}

In case of creation of model the task of heat conduction for the area representing the non-uniform system including a sensitive element of the resistive temperature detector, a protective cover (a metal jacket) and area in between, filled by powder of oxide of $\mathrm{Al}_{2} \mathrm{O}_{3}$ aluminum (fig. 1) is considered.

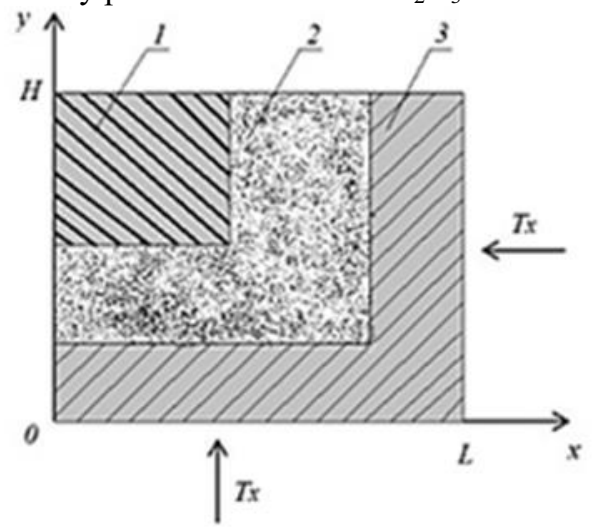

Figure 1. the Diagram of area of the solution of the task: 1 - sensitive element; 2 - isolation powder (Al2O3); 3 metal jacket (steel); $\mathrm{H}$ - height of a section of the RTD sensitive element; L - radius of the RTD sensitive element

At numerical modeling it is accepted that the sensor has the correct cylindrical form.

During research minimum necessary times of heating of the sensor, and also temperature fields in the RTD sensitive element were defined. The minimum duration of heating of the sensor corresponds to time necessary for this purpose, the deviation of temperature of a sensitive element 1 (fig. 1) from the taken didn't exceed a tolerance (table 1).

Table 1.Limits of allowed errors of RTD [9]

\begin{tabular}{|c|l|}
\hline Type RTD & Permissible deviation limit from rated direct current characteristic, ${ }^{\circ} \mathrm{C}$ \\
\hline$P t(\mathrm{C}$ tolerance class $)$ & $\pm(0,6+0,008 \cdot t)$ in the range of temperatures from -100 to $300{ }^{\circ} \mathrm{C} ;$ \\
\hline$C u(\mathrm{C}$ tolerance class $)$ & $\pm(0,5+0,0065 \cdot t)$ in the range of temperatures from -200 to $200{ }^{\circ} \mathrm{C} ;$ \\
\hline$N i(\mathrm{C}$ tolerance class $)$ & $\pm(0,3+0,008 \cdot t)$ in the range of temperatures from 0 to $180{ }^{\circ} \mathrm{C} ;$ \\
\hline
\end{tabular}

Where $t$ - temperature taken by the sensor, ${ }^{\circ} \mathrm{C}$. For area solutions of the task (fig. 1) are made the following sizes: $H=5 \mathrm{~mm} ; L=5 \mathrm{~mm}$.

\section{Mathematical model and decision methods}

The system of differential equations describing nonstationary process of heat transport in the TPS sensitive element:

$$
\begin{aligned}
& c_{1} \cdot \rho_{1} \cdot \frac{\partial T_{1}}{\partial t}=\lambda_{1}\left(\frac{\partial^{2} T_{1}}{\partial x^{2}}+\frac{1}{x} \cdot \frac{\partial T_{1}}{\partial x}+\frac{\partial^{2} T_{1}}{\partial y^{2}}\right), 0<x<x_{1}, y_{2}<y<H ; \\
& c_{2} \cdot \rho_{2} \cdot \frac{\partial T_{2}}{\partial t}=\lambda_{2}\left(\frac{\partial^{2} T_{2}}{\partial x^{2}}+\frac{1}{x} \cdot \frac{\partial T_{2}}{\partial x}+\frac{\partial^{2} T_{2}}{\partial y^{2}}\right), 0<x<x_{2}, y_{1}<y<y_{2} ; x_{1}<x<x_{2}, y_{2}<y<H ; \\
& c_{3} \cdot \rho_{3} \cdot \frac{\partial T_{3}}{\partial t}=\lambda_{3}\left(\frac{\partial^{2} T_{3}}{\partial x^{2}}+\frac{1}{x} \cdot \frac{\partial T_{3}}{\partial x}+\frac{\partial^{2} T_{3}}{\partial y^{2}}\right), 0<x<x_{3}, 0<y<y_{1} ; x_{2}<x<x_{3}, y_{1}<y<H .
\end{aligned}
$$

Where $x$ - radial coordinate, $\mathrm{m} ; y$ - axial coordinate, $\mathrm{m} ; \rho$ - density, $\mathrm{kg} / \mathrm{m}^{3} ; \mathrm{c}$ - specific heat capacity, $\mathrm{J} /\left(\mathrm{kg} \cdot{ }^{\circ} \mathrm{C}\right) ; \lambda$ - coefficient of heat conduction, $\mathrm{W} /\left(\mathrm{m} \cdot{ }^{\circ} \mathrm{C}\right)$; indexes: 1 - sensing element RTD, $2-$ powder of an oxide of aluminum, 3 - a protective cover; $T$ - measuring temperature,${ }^{\circ} \mathrm{C} ; t$ - time, c. 
The boundary conditions which have been set on an axis of symmetry $r=0$ :

$x=0, \frac{\partial T}{\partial x}=0$.

Boundary conditions on boundary $x=L$ :

$x=L ; T=T_{x}$.

$T_{x}$ - temperature of a heating element.

Boundary conditions on boundaries on an axis $y$ :

$y=H, \frac{\partial T}{\partial x}=0 ; y=0, T=T_{x}$.

At the internal borders of the area specified condition of fourth type:

Boundary «A sensitive element - the powder $\mathrm{Al}_{2} \mathrm{O}_{3}$ »

$$
\begin{array}{ll}
y_{2}<y<H ; & 0<x<x_{1} ; \\
T_{1}\left(x_{1}, y\right)=T_{2}\left(x_{1}, y\right) ; & T_{1}\left(x, y_{2}\right)=T_{2}\left(x, y_{2}\right) ; \\
-\left.\lambda_{1} \frac{\partial T_{1}}{\partial x}\right|_{x=x_{1}}=-\left.\lambda_{2} \frac{\partial T_{2}}{\partial x}\right|_{x=x_{1}} ; & -\left.\lambda_{1} \frac{\partial T_{1}}{\partial y}\right|_{y=y_{2}}=-\left.\lambda_{2} \frac{\partial T_{2}}{\partial y}\right|_{y=y_{2}} .
\end{array}
$$

Boundary «the powder $\mathrm{Al}_{2} \mathrm{O}_{3}$ - protective cover»:

$$
\begin{array}{ll}
y_{1}<y<H ; & 0<x<x_{2} ; \\
T_{2}\left(x_{2}, y\right)=T_{3}\left(x_{2}, y\right) ; & T_{2}\left(x, y_{1}\right)=T_{3}\left(x, y_{1}\right) ; \\
-\left.\lambda_{2} \frac{\partial T_{2}}{\partial x}\right|_{x=x_{2}}=-\left.\lambda_{3} \frac{\partial T_{3}}{\partial x}\right|_{x=x_{2}} ; & -\left.\lambda_{2} \frac{\partial T_{2}}{\partial y}\right|_{y=y_{1}}=-\left.\lambda_{3} \frac{\partial T_{3}}{\partial y}\right|_{y=y_{1}} .
\end{array}
$$

The area of the solution of the task (fig. 1) is broken into the uniform grid consisting of 200 nodes. The slot pitch on radial and axial coordinates is equal $2,5 \cdot 10^{-2} \mathrm{~mm}$. The step on a temporal grid changed in the range from $10^{-4}$ to $10^{-2} \mathrm{sec}$ for reduction of volume of computation and increase of accuracy of the decision.

System of equations 1-3 with the appropriate initial and boundary conditions decided using a method of finite differences [10]. The solution of the difference analogs of the differential equations representing linear algebraic equations was carried out by a local and one-dimensional method [10]. The pro-race method was applied to the decision of system of the difference equations on the basis of the implicit four-point diagram [10].

The conservatism verification of applied difference schemes was conducted to estimate the confidence of numerical simulation results similar to [11-13]) and the comparison with experiment results was accomplished.

\section{Results and discussion}

The constant values of heatphysical characteristics accepted at numerical research are given in table 2 .

Table 2. Heatphysical characteristics of materials RTD [14, 15]

\begin{tabular}{|c|c|c|c|}
\hline Name of material & $\lambda, \mathrm{W} /\left(\mathrm{m}^{\circ}{ }^{\circ} \mathrm{C}\right)$ & $\mathrm{c}, \mathrm{J} /\left(\mathrm{kg} \cdot{ }^{\circ} \mathrm{C}\right)$ & $\rho, \mathrm{kg} / \mathrm{m}^{3}$ \\
\hline Platinum & 70 & 134 & 21500 \\
\hline Cooper & 390 & 385 & 8890 \\
\hline Nickel & 92 & 500 & 8900 \\
\hline Poweder $\mathrm{Al}_{2} \mathrm{O}_{3}$ & 6,57 & 850 & 1520 \\
\hline Steel & 47 & 460 & 7800 \\
\hline
\end{tabular}

Approximation of dependences of heatphysical characteristics is executed by method of the smallest squares. The received approximating expressions in the considered range of temperatures are given in table 3 . 


\section{MATEC Web of Conferences}

Table 3. Approximating expressions of heatphysical properties of materials

\begin{tabular}{|c|c|c|}
\hline$\lambda(T x)=, \mathrm{W} /\left(\mathrm{m}^{\circ}{ }^{\circ} \mathrm{C}\right)$ & $\mathrm{c}(T x)=, \mathrm{J} /\left(\mathrm{kg} \cdot{ }^{\circ} \mathrm{C}\right)$ & $\rho(T x)=, \mathrm{K} \Gamma / \mathrm{M}^{3}$ \\
\hline \multicolumn{3}{|c|}{ Platinum } \\
\hline $\begin{array}{c}2 \cdot 10^{-11} \cdot T x^{4}-4 \cdot 10^{-8} \cdot T x^{3}+ \\
+3 \cdot 10^{-5} \cdot T x^{2}-0,0025 \cdot T x+71,761\end{array}$ & $-2 \cdot 10^{-6} \cdot T x^{2}+0,0288 \cdot T x+131,98$ & $-6 \cdot 10^{-5} \cdot T x^{2}-0,5956 \cdot T x+21486$ \\
\hline \multicolumn{3}{|c|}{ Cooper } \\
\hline $0,0002 \cdot T x^{2}-0,1371 \cdot T x+405,45$ & $-0,0001 \cdot T x^{2}+0,1455 \cdot T x+381,16$ & $-0,0089 \cdot T x^{2}+0,7483 \cdot T x+8919,3$ \\
\hline \multicolumn{3}{|c|}{ Nickel } \\
\hline$-0,0003 \cdot T x^{2}-0,0631 \cdot T x+92,312$ & $-3 \cdot 10^{-5} \cdot T x^{2}+0,4096 \cdot T x+432,56$ & $9 \cdot 10^{-16} \cdot T x^{2}-0,4 \cdot T x+8910,8$ \\
\hline
\end{tabular}

During research minimum necessary duration of execution of measurement with which the measurement error doesn't exceed the permissible deviations given in [10] was defined. The received results of necessary runtimes of measurements for the RTD different types are given in fig. 2 .

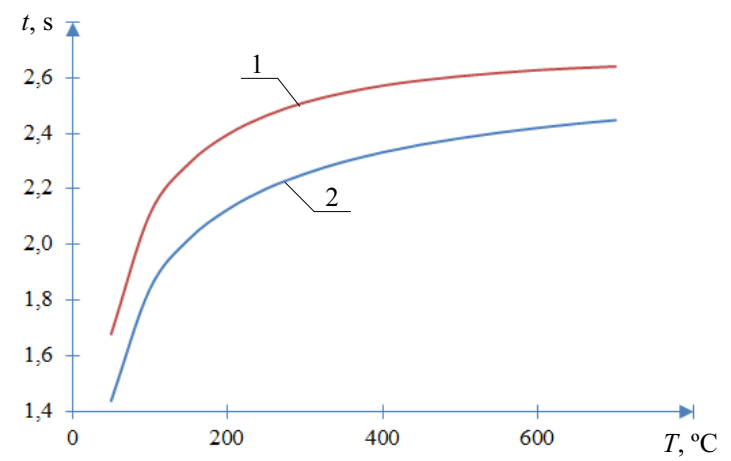

a)

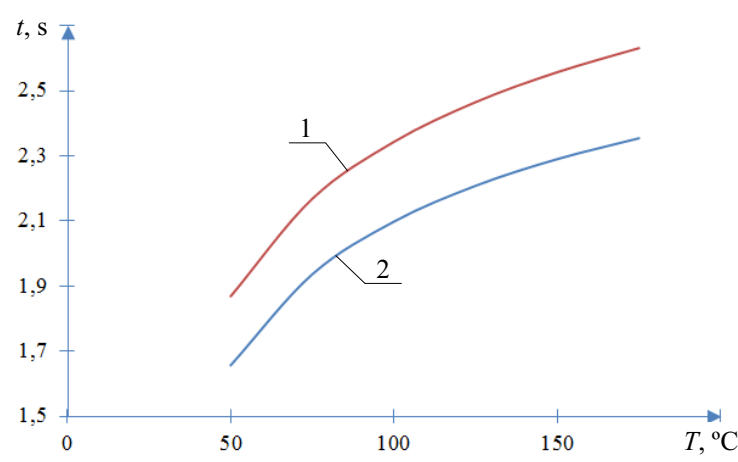

б)

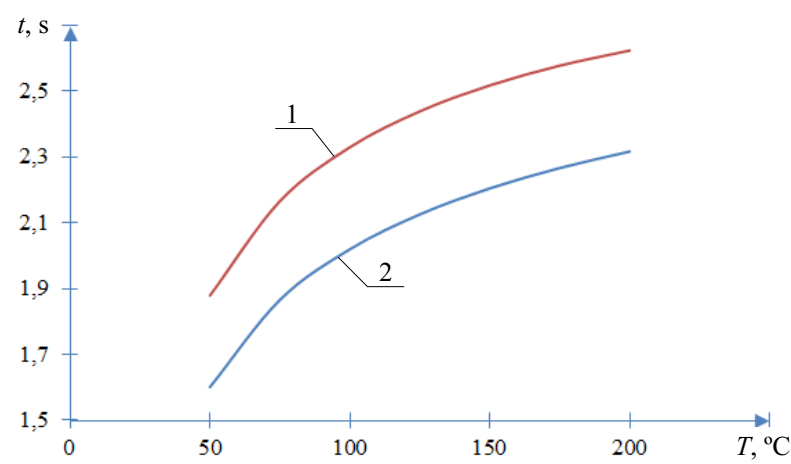

B)

Figure 2. Dependence of necessary duration of heating up of TPS on the taken temperature: a - platinum RTD; nickel RTD; in - copper RTD; 1 - the approximated heatphysical characteristics; 2 - constant heatphysical characteristics

From a figure 2 it is visible that the heating up necessary for duration received when using of the characteristics approximated the teplofi-zicheskikh exceed the similar values received when using constant heatphysical characteristics.

The numerical assessment of a relative deviation of necessary times of heating of the sensors received with use of constants and the approximated heatphysical characteristics for the RTD different types is given in table 4 . 
Table 4. Relative error of calculation of necessary duration of heating of RTD

\begin{tabular}{|c|c|c|c|}
\hline Температура, ${ }^{\circ} \mathrm{C}$ & Type $\mathrm{Pt}$ & Type Ni & Type Cu \\
\hline 50 & 14,303 & 11,349 & 14,795 \\
\hline 75 & 13,651 & 10,701 & 13,850 \\
\hline 100 & 12,749 & 10,457 & 12,305 \\
\hline 125 & 12,908 & 10,426 & 12,431 \\
\hline 150 & 11,873 & 10,442 & 12,064 \\
\hline 175 & 12,916 & 10,528 & 11,700 \\
\hline 200 & 11,269 & - & - \\
\hline 250 & 10,674 & - & - \\
\hline 300 & 10,231 & - & - \\
\hline 350 & 9,741 & - & - \\
\hline 400 & 9,331 & - & - \\
\hline 450 & 8,915 & - & - \\
\hline 500 & 8,557 & - & - \\
\hline 550 & 8,212 & - & - \\
\hline 600 & 7,915 & - & \\
\hline 650 & 7,590 & - & \\
\hline 700 & 7,308 & - & \\
\hline
\end{tabular}

Deviations of the received results for the researched RTD types make: for copper RTD - from $11,7 \%$ to $14,8 \%$, for platinum RTD - from $7,3 \%$ to $14,3 \%$, for nickel - from $10,5 \%$ to $11,4 \%$.

Distribution of temperatures on RTD thickness, received when using of the approximated and constant heatphysical characteristics is shown, respectively, in figures $3 \mathrm{a}$ and $3 \mathrm{~b}$.

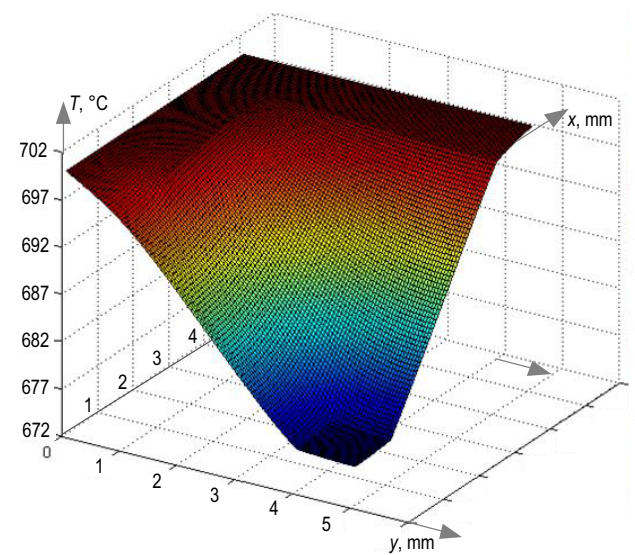

a)

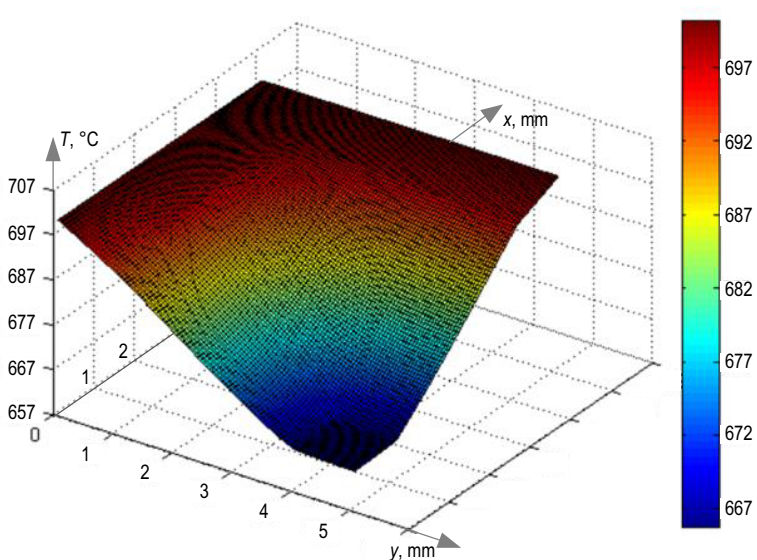

b)

Figure 3. Temperature fields in a sensitive element of platinum RTD at measurement of temperature $700 \mathrm{zs}$, received by means of constants (1) and the approximated (2) and heatphysical characteristics

From fig. 3 it is visible that distribution of temperatures on a layer of a sensitive element of the thermoconverter of resistance has nonlinear character. Taking into account that duration of heating is both cases (fig. $3 \mathrm{a}$ and $3 \mathrm{~b}$ ) it was limited and I made 2 seconds, it is possible to draw a conclusion that when using of the approximated heatphysical characteristics are received big heating duration. 


\section{MATEC Web of Conferences}

\section{Conclusion}

In the article integrated characteristics of process of heattransfer are provided in a sensitive element of thermoconverters of resistance: heatings of sensors minimum necessary for duration (for copper, nickel and platinum RTD), temperature fields in sensitive elements of sensors. The specified integrated characteristics are received with use of constants and the approximated heatphysical characteristics. It is established that relative deviations of results are in range from $7,3 \%$ to $14,8 \%$ and depend on the RTD type and the taken temperature.

This work was supported by the Russian Foundation for Basic Research (No. 14-08-00057).

\section{References}

1. G.R. McMillan, C.M. Toarmina, Advanced Temperature Measurement and Control (Research Triangle Park, NC: International Society of Automation, USA, 2011)

2. P.R.N. Childs, Practical Temperature Measurement (Oxford: Butterworth-Heinemann, GB, 2001).

3. S.K. Sen, Measurement, 39 (5), 477 (2006)

4. P. Chen, L. Guo, G. Lu, C. Jin, Appl. Mech. Mater., 721, 513 (2014)

5. Y. K. Atroshenko, I.P. Ozerova, P.A.Strizhak, Adv. Mater. Res., 1040, 965

6. E.N. Senkin, A.A. Okunev, Modern Engineering. Science and Education [in Russian], 4, 847 (2014)

7. R.I. Esman, V.A. Ustimovich, News of Higher Educational Establishments and Power Unions of CIS. Energetic [in Russian], 6, 32 (2007)

8. P.K. Krajewski, G. Piwowarsi, J. Buraś, W.K. Krajewski, P. Rutkowski, D. Szeliga, Arch. Metall. Mater., 59, 1055 (2014)

9. GOST 6651-2009 Thermal resistance of platinum, copper and nickel. General technical requirements and test methods, Moscow [in Russian] (2009)

10. A.A. Samarskii, The Theory of Difference Schemes (Marcel Dekker, Inc., USA, 2001).

11. G.V. Kuznetsov G.V. and P.A. Strizhak, Int. J. Heat and Mass Transfer, 53, 923 (2010)

12. D.O. Glushkov, G.V. Kuznetsov, P.A. Strizhak, Russ. J. Phys. Chem. B., 1000 (2011)

13. D.O. Glushkov, P.A. Strizhak, J. Eng. Thermophys., 69 (2012)

14. E.V. Zinovyev, Thermal properties of metals at high temperatures, Metallurgy, Moscow [in Russian], 1989

15. R. Hultgren. Selected Values of the Thermodynamic Properties of Binary Alloys (USA, American Society for Metals, 1973) 